Gynecologic and

Obstetric Investigation
Received: November 10, 2011

Accepted after revision: July 6, 2012

Published online: September 5, 2012

\title{
A Prospective Study of Rollerball Endometrial Ablation in the Management of Refractory Recurrent Symptomatic Endometrial Hyperplasia without Atypia
}

\author{
Muhittin Eftal Avci ${ }^{\mathrm{a}}$ Salih Sadik ${ }^{\mathrm{b}}$ Mustafa Gazi Uçar ${ }^{\mathrm{c}}$ \\ a Departments of Obstetrics and Gynecology, Ümraniye Education and Research Hospital, Istanbul, \\ ${ }^{b}$ Departments of Obstetrics and Gynecology, Aegean Training and Research Hospital, Izmir, and 'Departments of \\ Obstetrics and Gynecology, Konya Education and Research Hospital, Konya, Turkey
}

\section{Key Words}

Rollerball endometrial ablation - Refractory recurrent symptomatic endometrial hyperplasia

\begin{abstract}
Backgrounds: Menorrhagia - heavy, extended or irregular menstruations - may be associated with endometrial hyperplasia. The aim of this study was to evaluate the clinical efficacy and safety of transcervical rollerball endometrial ablation (EA-R) and to discuss surgical outcomes in patients with simple endometrial hyperplasia without atypia who have had a history of medical treatment failure or recurrence. Methods: A prospective study was designed. Thirty women underwent EA-R. Preoperative and postoperative menstrual status, sexual activity, and satisfaction with the procedure were assessed. Complications, clinical outcomes, and need for re-intervention were evaluated. Results: No major complications occurred. All patients were discharged from hospital within $24 \mathrm{~h}$. A reduction of menorrhagia was observed in patients as follows: 17 patients (56.67\%) had amenorrhea, 10 (33.33\%) hypomenorrhea, and 2 (6.67\%) eumenorrhea. Hysterectomy was performed only in 1 patient who was unresponsive to ablation treatment. Conclusions: In selected patients who have persistent uterine bleeding not respon-
\end{abstract}

sive to conservative therapy, low risk for future endometrial cancer, and wish to retain their uterus, EA-R treatment is safe, effective, and might be an alternative to hysterectomy with good toleration and high rate of patient satisfaction. The advantages of EA-R include low incidence of complications, lower morbidity, shorter hospitalization, and faster recovery.

Copyright $\odot 2012$ S. Karger AG, Basel

\section{Introduction}

Endometrial hyperplasia $(\mathrm{EH})$ is an increase in the number of cells in the inner lining of the uterus. An excessive proliferation of the endometrial cells results in glandular enlargement and budding. The causes of $\mathrm{EH}$ include high levels of estrogens, combined with insufficient levels of the progesterone-like hormones which ordinarily counteract estrogen's proliferative effects on endometrium. $\mathrm{EH}$ is a heterogeneous set of pathologic lesions that range from mild, reversible glandular proliferations to direct cancer precursors. The exact mechanism is uncertain but is thought to be caused by a dysfunction of the hypothalamic-pituitary-ovarian axis [1]. Menometrorrhagia is the significant cause of morbidity related with EH. In addition, menstrual discomfort and

\section{KARGER \\ Fax +4161306 1234 \\ E-Mail karger@karger.ch}

www.karger.com
(C) 2012 S. Karger AG, Basel

0378-7346/12/0744-0282\$38.00/0

Accessible online at:

www.karger.com/goi
Mustafa Gazi Uçar, MD

Konya Eğitim ve Araştırma Hastanesi

Necip Fazil Mah. Atesbazi Sok. Meram Yeniyol

TR-42040 Meram Konya (Turkey)

Tel. +90 533939 0786, E-Mail mustafa_gazi_ucar@hotmail.com 
its influence have a negative impact on women's quality of life, daily activities, and psychosocial life. Excessive blood loss may result in anemia, fatigue, and syncope. The first-line treatment in symptomatic simple EH without atypia is usually medical. The medical options include intermittent or continuous use of progestin, the combined oral contraceptive pill and the levonorgestrelreleasing intrauterine system [2]. Specific treatment may be required for disorders such as polycystic ovarian syndrome, obesity or other diseases related with endocrine abnormalities. However, medical treatment options are not an adequate approach in some circumstances, and a conservative surgical technique must be proposed; the choices include first- or second-generation endometrial ablation (EA) techniques, such as rollerball, laser, electrode ablation, cryotherapy, microwave, and radiofrequency. Hysterectomy should be performed in selected patients who do not desire fertility. Hysterectomy is obviously $100 \%$ effective in stopping bleeding, but it is not cost effective and can cause severe complications [3]. EA has been shown to be an alternative to hysterectomy and, also, this technique is a well-established means of treating heavy menstrual bleeding that has a number of advantages over hysterectomy.

The purpose of this prospective study was to evaluate the clinical efficacy and safety of transcervical rollerball EA (EA-R) and to discuss surgical outcomes in patients with simple EH without atypia who had a history of medical treatment failure or recurrence.

\section{Materials and Methods}

A prospective study was designed between January 2006 and December 2007 at Aegean Obstetrics and Gynecology Training and Research Hospital. Thirty women underwent EA-R without endometrial preparation by a single surgeon. All patients in the study did not wish to become pregnant in the future and were keen to preserve their uterus. They were diagnosed preoperatively by means of physical examination, cervical smear, transvaginal pelvic ultrasonography, and endometrial biopsy. Dilation and curettage was performed for the diagnosis of $\mathrm{EH}$ without atypia before the surgery. The patients with large uterine size (larger than the size at 12 weeks' gestation), pelvic-adnexal pathology, presence of cytological atypia, and complex classification of architectural abnormalities were excluded from the study. The decision to proceed with a hysteroscopic EA-R was made after a discussion between the operating surgeon and the patient. This prospective trial was conducted in our institution after approval by the Institutional Ethics Committee. Informed consent was obtained from all patients in the study.

Thirty women with intractable uterine bleeding who had a diagnosis of simple $\mathrm{EH}$ without atypia were subjected to hysteroscopic EA-R. Before surgery, 2 g cefazolin was administered in- travenously and $100 \mu \mathrm{g}$ vaginal misoprostol was used for priming the cervix to facilitate dilatation of the cervical canal. Neither pharmacological nor surgical pre-thinning of the endometrium was used.

The interventions were performed under spinal or general anesthesia. After standard operative hysteroscopic preparation procedures (e.g. positioning, cervical dilatation), 1.5\% glycine solution was used for uterine distension and irrigation. For EA, rollerball electrodes of $5 \mathrm{~mm}$ diameter were used with $120 \mathrm{~W}$ cutting current. To ensure that the tissue destruction was deep enough, the electrode was carefully moved up to see a white halo of desiccated endometrium. The posterior, lateral, and anterior walls of the endometrium were coagulated. In order to avoid fluid overload, fluid balance was carefully monitored. In the early postoperative period, patients' electrolyte levels were checked and given special attention to avoid electrolyte imbalance, extravasations, and transurethral resection syndrome.

The routine follow-up examinations were done at postoperative day 7, and 1 and 6 months after surgery. The postoperative examination at 6 months included pelvic examination, assessment of endometrial thickness, morphology, and histology with aspiration biopsy (pipelle). Demographic features of the patients were recorded. We used a questionnaire to assess preoperative and postoperative menstrual status, sexual activity, and satisfaction with the procedure. Complications, clinical outcomes, and need for re-intervention were evaluated.

The following were considered successful management criteria of the procedure: amenorrhea, endometrial thickness $\leq 4 \mathrm{~mm}$, or histopathologically normal findings without hyperplasia. Data of the study were analyzed with SPSS version 13.0.

\section{Results}

A total of 30 women with menorrhagia due to simple $\mathrm{EH}$ without atypia underwent hysteroscopic EA-R, and none of them had undergone previous EA. The mean age of the patients was $45.16 \pm 3.48$ years (range $40-54$ ). The mean parity was $3.1 \pm 1.3$ (range $2-8$ ), and the mean duration of the menstrual period was $8.36 \pm 1.95$ days. The median duration of menstrual irregularities was 18 months (range 8-120). All patients had previously undergone medical treatment with progesterone. Preoperative mean hemoglobin level was $8.52 \pm 1.55 \mathrm{~g} / \mathrm{dl}$ (range 5.512).

All patients had a history of medical treatment for anemia. Five patients had a blood transfusion history due to heavy menstrual bleeding. The body mass index (BMI) of 24 patients was above the normal range. Moreover, $43 \%$ of patients had obesity (BMI $>30)$, putting them at a high risk of future endometrial cancer. The patients' demographical properties are represented in table 1.

The procedures were performed under spinal anesthesia in 28 cases and, because of morbid obesity (BMI $>40)$, endotracheal anesthesia in 2 cases. The mean operation 
Table 1. Patients' demographic features

\begin{tabular}{lc}
\hline Age, years & $44.5(40-54)$ \\
Parity & $3.1 \pm 1.3$ \\
Duration of menstrual period, days & $8.36 \pm 1.95$ \\
Duration of menorrhagia, heavy, extended or & \\
$\quad$ irregular menstruation history, months & $18(8-120)$ \\
Preoperative mean hemoglobin level, g/dl & $8.52 \pm 1.55$ \\
History of medical treatment with progestins & All patients \\
History of anti-anemic medical treatment & All patients \\
History of blood transfusion & $5(16.6)$ \\
BMI & \\
$\quad<25$ & $6(20)$ \\
$\quad 25-30$ & $11(36.7)$ \\
$\quad 31-35$ & $8(26.7)$ \\
$\quad 35$ & $5(16.6)$ \\
Cigarette smokers & $11(36.7)$ \\
Comorbid disease & \\
$\quad$ Diabetes mellitus & $5(16.6)$ \\
$\quad$ Hypertension & $3(10)$ \\
Hypothyroidism & $3(10)$ \\
Patients with complaints of premenstrual & \\
$\quad$ symptoms & $22(73.3)$ \\
\hline
\end{tabular}

Values are means with ranges in parentheses, means \pm SD or numbers with percentages in parentheses.

time was $20.46 \pm 1.91 \mathrm{~min}$ (range 17-26). In addition to the standard procedure, hysteroscopic polypectomy was performed in 1 patient whose operation duration was the longest $(26 \mathrm{~min})$. The mean total distension and irrigation fluid used was calculated as $4.97 \pm 0.35$ liter with $0.15 \pm 0.08$ liter fluid deficit. The patients' operative findings and outcomes are detailed in table 2.

All patients were discharged from hospital within $24 \mathrm{~h}$. No major complications occurred. In 1 patient, cervical laceration occurred intra-operatively. Two patients had nausea and vomiting symptoms in the early postoperative period. Three days after discharge, 1 patient was admitted to our center with a complaint of high fever and foul-smelling vaginal leakage. She was hospitalized again and treated successfully with second-generation cephalosporin and metronidazole. Long-term complications included 2 cases of pelvic pain similar to dysmenorrhea, and these patients were treated with non-steroidal antiinflammatory drugs.

Menstrual status was assessed 6 months postoperatively. Most of the patients who underwent hysteroscopic EA-R had a successful reduction of menorrhagia. The reduction was observed as follows: 17 patients $(56.67 \%)$ had amenorrhea, 10 (33.33\%) hypomenorrhea, and 2 (6.67\%) eumenorrhea. Only 1 patient who was unresponsive to
Table 2. Patients' operative findings and outcomes

\begin{tabular}{lc}
\hline Operation time, min & $20.46 \pm 1.91$ \\
Total distension and irrigation fluid, liter & $4.97 \pm 0.35$ \\
View of endometrial cavity during operation & \\
Atrophy and hyperemia & $18(60)$ \\
Regular & $9(30)$ \\
Atrophy & $2(6.67)$ \\
Polyp & $1(3.33)$ \\
Fluid deficit, liter & $0.15 \pm 0.08$ \\
Anesthesia & \\
Spinal & $28(98.33)$ \\
Endotracheal & $2(6.67)$ \\
\hline
\end{tabular}

Values are means \pm SD or numbers with percentages in parentheses.

first ablative treatment required a further intervention and did not consent to undergoing a repetition of the rollerball procedure. In that case, hysterectomy was performed.

Endometrial thickness and cytological sampling 6 months postoperatively were also evaluated. Endometrial thickness was $\leq 4 \mathrm{~mm}$ in 17 cases, and probe curettage results revealed insufficient endometrial sampling. Proliferative endometrial histology was found in 12 patients; 6 of them had $5 \mathrm{~mm}$ and 6 had $6 \mathrm{~mm}$ endometrial thickness. Women with a complaint of heavy menstrual bleeding who underwent hysterectomy had $8 \mathrm{~mm}$ endometrial thickness and biopsy finding was simple $\mathrm{EH}$ without atypia.

The majority of the women were satisfied with the procedure and they pointed out that they would recommend this treatment to patients like themselves. The subjective effects of EA are presented in table 3.

\section{Discussion}

Menometrorrhagia is the significant cause of morbidity related with $\mathrm{EH}$. The prevalence of abnormal uterine bleeding is estimated at $11-13 \%$ of the general population and increases with age, reaching $24 \%$ in those aged $36-40$ years [3].

Women with abnormal uterine bleeding and simple EH without atypia have a variety of therapeutic options including medical and surgical procedures. However, several surgical options must be proposed to patients in whom medical treatment is unsuccessful or contraindicated. The surgical treatment modalities include hyster- 
Table 3. Subjective postoperative effects of EA-R

\begin{tabular}{lc}
\hline Sexual life & \\
Better & $20(66.7)$ \\
Same & $9(30.0)$ \\
Worse & $1(3.33)$ \\
Daily activities & $25(83.34)$ \\
Better & $4(13.33)$ \\
Same & $1(3.33)$ \\
Worse & \\
Treatment satisfaction & $24(80.0)$ \\
Yes & $1(3.33)$ \\
No & $5(16.67)$ \\
Not sure & $24(80.0)$ \\
Would you recommend this treatment to someone else? \\
Yes, certainly & $5(16.67)$ \\
Maybe & $1(3.33)$ \\
No &
\end{tabular}

Values are numbers with percentages in parentheses.

ectomy and minimal invasive interventions such as EA. There is a longstanding controversy as to whether hysterectomy is overused or more conservative surgery may be just as effective with fewer adverse outcomes [4]. In an attempt to provide a less invasive alternative to hysterectomy, new techniques such as EA-R were developed [5]. This treatment modality is associated with lower morbidity, shorter hospitalization, faster recovery, and reduced treatment costs when compared with traditional hysterectomy [6]. Because of its relative simplicity, effectiveness, and low complication rate, EA-R has been attractive to physicians and patients alike as a good alternative to endometrial laser ablation [7].

Many published data point out the clinical efficacy and safety of EA techniques [8]. These modalities also have financial implications for healthcare providers [9]. Dickersin et al. [10] reported that hysterectomy was associated with more adverse events; nevertheless, with EA, re-operation was more frequently required. Goldfarb [11] claimed that after long-term follow-up ( $>5$ years), approximately 1 out of 5 women who have undergone EA resection will require a hysterectomy. The existence of uterine myomas at the time of ablation can be considered a risk factor for the subsequent need for hysterectomy [12]. It has previously been shown that the success rate of EA declines with the length of follow-up $[12,13]$. In our study, a complete clinical examination was done and we did not include any cases with large uterine size (larger than the size at 12 weeks' gestation) and pelvic-adnexal pathology. Patient selection is important as well as the experience of the operator. Only 1 patient required a further intervention and, in this case, hysterectomy was performed due to EA failure. There was no other indication for hysterectomy in our 3-year follow-up.

The power setting is less important than the duration of tissue contact with the electrode. In vivo studies have shown that the thermal effect of rollerball ablation extends to a depth of just $<4 \mathrm{~mm}$ [14]. The rollerball electrode contact duration with endometrial tissue must be well balanced to avoid incomplete treatment or uterine perforation, especially when treating the uterine cornu as the myometrium is thinnest in the cornual region. In our study, only 1 patient underwent reoperation and we did not experience any uterine perforation. No major complications occurred and we achieved amenorrhea in over half of the patients treated with EA-R (17 patients, 56.67\%).

Although the laser ablation, loop resection or rollerball ablation complication profile is slightly different, menstrual improvement seems to be similar for these three techniques according to the published data [15-17]. When comparing rollerball ablation with other techniques, it has a shorter learning curve and operation time than resection. The complication rates of rollerball ablation are lower than in laser ablation, and operation times are similar for these two techniques [15-17]. In our study, the mean operating time was $20.46 \pm 1.91 \mathrm{~min}$ (range 17-26). After experience with an increasing number of cases where rollerball ablation is applied, a surgeon's operation time gradually becomes shorter.

In our study, we performed hysteroscopic EA without endometrial preparation (pharmacological or surgical pre-thinning of the endometrium) as suggested in the study of Rosati et al. [18] because of potential adverse effects of hormones containing drugs and a reduced hysteroscopic visualization caused by curettage. We did not observe any negative impact of skipping the preoperative endometrial preparation in our study when considering clinical and surgical outcomes.

The majority of the women were satisfied with the procedure and they pointed out that they would recommend this treatment to other patients. According to our study, the procedure had a favorable impact on patients' daily activities and quality of life. Sexual life is an important aspect of quality of life that may be significantly altered following surgical treatment in patients with persistent uterine bleeding not responsive to conservative therapy.

In a population-based study dealing with psychosexual health 5 years after transcervical endometrial resection/ablation and hysterectomy, McPherson et al. [19] re- 
ported that psychosexual problems were higher after hysterectomy when compared with less invasive procedures. We have also not observed any negative effect on sexual life and have had better results with EA-R.

Pregnancy is possible after EA-R; this procedure cannot guarantee sterility. After surgery, women who have undergone EA need to use effective contraception. A disadvantage of rollerball ablation is that it cannot provide endometrial tissue for histology. Therefore, it is essential to obtain an endometrial biopsy before performing rollerball ablation.

Occurrence of endometrial cancer after EA is low, but it must also be emphasized that after ablation, patients with risk factors for endometrial cancer require close follow-up [20]. EA itself does not seem to increase the risk of consequent endometrial cancer [21,22]. However, ablation results in intrauterine adhesions that may mask bleeding, which is the major symptom of endometrial cancer, and/or interfere with endometrial sampling. Furthermore, histologic examination of samples from women who have undergone EA may be difficult [23-25]. AlHilli et al. [20] found that most patients who develop endometrial cancer after an ablation had risk factors including hyperplasia that was unresponsive to medical treatment. They concluded that ablations should not be done in these patients. Endometrial biopsies, diagnostic hysteroscopy, and saline infusion sonograms are often unreliable [26]. To resolve this dilemma, an ultrasoundguided operative hysteroscopy may be necessary, but the dense scarring can distort the endometrial cavity, making it difficult to access all endometrial tissues [24, 26]. Complete atrophy and partial adhesion or obliteration of the cavity and fibrosis were observed at second-look hysteroscopy $[24,25]$.

As a conclusion, this technique is more compatible with the modern concept of fast-track rehabilitation and minimally invasive surgery when compared with hysterectomy. Rollerball treatment is associated with lower morbidity, shorter hospitalization, and faster recovery. It is not intended to replace hysterectomy; of course, hysterectomy is obviously $100 \%$ effective in stopping bleeding. In selected patients with persistent uterine bleeding not responsive to conservative therapy and with a low risk for future endometrial cancer rollerball ablation may be an alternative to hysterectomy. EA-R is safe and effective for patients with symptomatic EH without atypia and who wish to retain their uterus. Psychological effects and anxiety related to organ loss can be prevented. It must be emphasized that this study was limited by a lack of long-term outcomes, and on this basis, a more comprehensive and detailed study should be undertaken. Further prospective randomized controlled trials are necessary to evaluate long-term outcomes.

\section{References}

1 Livingstone M, Fraser IS: Mechanisms of abnormal uterine bleeding. Hum Reprod Update 2002;8:60-67.

-2 Marret H, Fauconnier A, Chabbert-Buffet N, Cravello L, Golfier F, Gondry J, Agostini A, Bazot M, et al: Clinical practice guidelines on menorrhagia: management of abnormal uterine bleeding before menopause. Eur J Obstet Gynecol Reprod Biol 2010;152:133137.

3 Lethaby A, Hickey M, Garry R, Penninx J: Endometrial resection/ablation techniques for heavy menstrual bleeding. Cochrane Database Syst Rev 2009;7:CD001501.

4 Dickersin K, LeMaire GS: Hysterectomy; in Goldman MB, Hatch MC (eds): Women and Health. San Diego, CA, Academic Press, 2000.

5 Papadopoulos NP, Magos A: First-generation endometrial ablation: roller-ball versus loop versus laser. Best Pract Res Clin Obstet Gynaecol 2000;21:915-929.
6 Morgenthal CB, Richards WO, Dunkin BJ, Forde KA, Vitale G, Lin E, SAGES Flexible Endoscopy Committee 2007: The role of the surgeon in the evolution of flexible endoscopy. Surg Endosc 2007;21:838-853.

7 Valle RF: Roller-ball endometrial ablation. Baillieres Clin Obstet Gynaecol 1995;9:299316.

-8 Varma R, Soneja H, Samuel N, Sangha E, Clark TJ, Gupta JK: Outpatient thermachoice endometrial balloon ablation: longterm, prognostic and quality-of-life measures. Gynecol Obstet Invest 2010;70:145148.

-9 Madhu CK, Nattey J, Naeem T: Second generation endometrial ablation techniques: an audit of clinical practice. Arch Gynecol Obstet 2009;280:599-602.

10 Dickersin K, Munro MG, Clark M, Langenberg P, Scherer R, Frick K, et al: Hysterectomy compared with endometrial ablation for dysfunctional uterine bleeding: a randomized controlled trial. Obstet Gynecol 2007; 110:1279-1289.
11 Goldfarb HA: Hysterectomy after endometrial ablation-resection. J Minim Invasive Gynecol 2005;12:298.

12 Martyn P, Allan B: Long-term follow-up of endometrial ablation. J Am Assoc Gynecol Laparosc 1998;5:115-118.

13 Seidman DS, Bitman G, Mashiach S, Hart S, Goldenberg M: The effect of increasing age on the outcome of hysteroscopic endometrial resection for management of dysfunctional uterine bleeding. J Am Assoc Gynecol Laparosc 2007;7:115-119.

14 Duffy S, Reid PC, Sharp F: In-vivo studies of uterine electrosurgery. Br J Obstet Gynaecol 1992;99:579-582.

15 Baggish MS, Sze E: Endometrial ablation: a series of 568 patients treated over an 11-year period. Am J Obstet Gynecol 1996;74:908913. 
16 Overton C, Hargreaves J, Maresh M: A national survey of the complications of endometrial destruction for menstrual disorders: the MISTLETOE study. Minimally Invasive Surgical Techniques - Laser, EndoThermal or Endoresection. Br J Obstet Gynaecol 1997; 104:1351-1359.

17 Boujida VH, Philipsen T, Pelle J, et al: Fiveyear follow-up of endometrial ablation: endometrial coagulation versus endometrial resection. Obstet Gynecol 2002;99:988-992.

18 Rosati M, Vigone A, Capobianco F, Surico D, Amoruso E, Surico N: Long-term outcome of hysteroscopic endometrial ablation without endometrial preparation. Eur J Obstet Gynecol Reprod Biol 2008;138:222-225.

19 McPherson K, Herbert A, Judge A, Clarke A, Bridgman S, Maresh M, Overton C: Psychosexual health 5 years after hysterectomy: population-based comparison with endometrial ablation for dysfunctional uterine bleeding. Health Expect 2005;8:234-243.
20 AlHilli MM, Hopkins MR, Famuyide AO: Endometrial cancer after endometrial ablation: systematic review of medical literature. J Minim Invasive Gynecol 2011;18:393-400.

21 Neuwirth RS, Loffer FD, Trenhaile T, Levin $\mathrm{B}$ : The incidence of endometrial cancer after endometrial ablation in a low-risk population. J Am Assoc Gynecol Laparosc 2004;11: 492.

22 Krogh RA, Lauszus FF, Guttorm E, Rasmussen K: Surgery and cancer after endometrial resection. Long-term follow-up on menstrual bleeding and hormone treatment by questionnaire and registry. Arch Gynecol Obstet 2009;280:911.
3 Ahonkallio SJ, Liakka AK, Martikainen HK, Santala MJ: Feasibility of endometrial assessment after thermal ablation. Eur J Obstet Gynecol Reprod Biol 2009;147:69.

24 Onoglu A, Taskin O, Inal M, Sadik S, Simsek M, Akar M, Kursun S, Mendilcioglu I, Postaci $\mathrm{H}$, Ispahi C: Comparison of the long-term histopathologic and morphologic changes after endometrial rollerball ablation and resection: a prospective randomized trial. J Minim Invasive Gynecol 2007;14:39-42.

25 Taskin O, Onoglu A, Inal M, Turan E, Sadik S, Vardar E, Postaci H, Wheeler JM: Longterm histopathologic and morphologic changes after thermal endometrial ablation. J Am Assoc Gynecol Laparosc 2002;9:186190.

26 McCausland AM, McCausland VM: Longterm complications of minimally invasive endometrial ablation devices. J Gynecol Surg 2010;26:133-148. 